\title{
Alcohol health promotion research and policy in the Nordic countries - a literature review 1986-2008
}

\section{Stefan Thorpenberg}

\begin{abstract}
The problem with culture influencing research is visible in Nordic alcohol health promotion research. This study includes peer reviewed articles in alcohol health promotion in the Nordic countries and analyses the content of top-down vs. bottomup, and individual vs. community/governmental approaches for health promotion activities. The results shows that Sweden, Finland, Norway and Iceland tend to aim for reducing alcohol use in general, in order to decrease the incidence of alcohol related problems. Swedish articles are more often top-down, and discuss government regulations for the purpose. The Danish approach is more bottom-up and shows trust in the individuals abilities to take care of his/her health issues. The results from the research cannot serve as a guide for ordinary citizens and there is a need for a policy discussion on these issues in health promotion research, as well as policy circles.
\end{abstract}

Keywords: health promotion, alcohol research, alcohol policy

For many decades the Nordic countries have been seen as exemplary models for international welfare policies, and Scandinavian scholars as pioneers in public health research worldwide. However, the picture of a unified Nordic welfare policy has recently been questioned by Signild Vallgårda who has pointed out the differences between the countries in an article based on policy documents from Sweden, Norway and Denmark. Her analysis show that Danish public health programs often have a more liberal view on health, where the individual is responsible for his/her own health. The Norwegian programs have a slightly different social liberal perspective and emphasize the need for the individual to strengthen his/her position in health issues. The Swedish programs, on the other hand, focuses on inequality issues and its importance for the public health. The state and politicians are given an important role, which according to Vallgårda resembles a social democratic welfare ideal (Vallgårda, 2007).

The question is if these political and cultural differences between the Nordic countries also are present in research material such as international peer reviewed journals. Traditionally researchers are supposed to present 
their results in an objective, neutral and disinterested way, and to be autonomous to their own culture, social interests and political circumstances. This article illustrates that the differences between the countries are visible already in general health promotion articles. With a focus on the more controversial alcohol issues in health promotion, the differences become obvious. The findings show that researchers in such an applicable activity as health promotion research reflect its cultural context. Alcohol promotion research has an important impact on alcohol policies in general, and the differences between the Nordic countries shown in this article can also be seen on an international scale, which ought to inspire further policy discussions in the health promotion research area.

Recently it has been discussed if a change of the original aims of the Ottawa Charter has taken place. Ottawa Charter was the first to outline the health promotion agenda in 1986. Christine Porter has pointed out the discursive differences between the Ottawa Charter, compared to the Bangkok Charter from 2005. According to Porter the ideals in Ottawa Charter focused on social justice, while the Bangkok Charter only aimed to improve health opportunities. The view that educated people should be able to strengthen public participation in the direction of health matters, has also changed to a demand for proven policy, which leads to a focus on strong intergovernmental agreements and government incentives and regulations. Therefore, the general perspective on health promotion can be summarized as a change from bottom-up to top-down (Porter, 2006).

This article discusses these discursive changes with examples from the Nordic research of alcohol health promotion, but starts by giving a brief historical background to the differences and eventual changes in health promotion research. Based on the findings in the study of articles with the term "health promotion" as a keyword in the four most common databases for research articles, it seems like the bottom-up approach is more common in Denmark and Norway, and the top-down approach more common in Sweden and Finland. These trends are present already from 1986 up to now in the different countries, i.e. it is not possible to see a general change depending on the Bangkok Charter from 2005. However, the differences between the Nordic countries became more visible when only alcohol health promotion articles were examined. While Denmark often has the same bottom-up approach to alcohol issues, all alcohol health promotion articles in Sweden show a top-down perspective. The reason for these quite strong differences in research directions between the Nordic countries must probably be sought outside the academic sphere. However, this article not only discusses alcohol health promotion research in the Nordic countries but also tries to picture two discourses working side by side in international health promotion research from its start in the middle of the seventies.

\section{Background: Ottawa and Bangkok Charter, Modernity, and the Nordic countries}

According to Christine Porter there has been a change in the agenda of health promotion since the Bangkok Charter in 2005. One difference is a change of focus from new social movements and ecosocial justice, to new capitalism of law and economics (Porter, 2006). However, Marc Lalonde's famous report from 1974 shows 
that there seems to be two discourses at hand already from the start. According to the report, which was the inspiration for the later health promotion direction in public health, there were economical motives for the health policy change. At the time Lalonde was minister of health and welfare in Canada representing Trudeau's liberal government, and in the report he pointed out problems with the costs for ill-health, which acquired a major part of the budget of the Canadian public sector:

...there is a paradox of everyone
agreeing to the importance of research
and prevention yet continuing to
increase disproportionately the
amount of money spent on treating
existing illness. Public demand for
treatment services assures these
services of financial resources.
No such public demand exists for
research and preventive measures. As
a consequence, resources allocated for
research, teaching and prevention are
generally insufficient (Lalonde, 1974,
p. 30).

Therefore, an economical motive for health promotion seems to be one of the starting points for politicians, as a way to lower the costs for the public sector. The same approach is at hand also in the speech given by Jake Epp at the Ottawa conference in 1986. Epp was a later successor of Lalonde as minister of health and welfare in Canada, representing Mulroney's Conservative Party. He addressed the importance of the participation of ordinary citizens in the promotive process:

A new approach to public participation must be built on a strong history of voluntarism in this country...There is a growing pattern of self-help amongst those with chronic diseases and movement towards independent living among the disabled. The spirit of community participation is strong in Canada (Epp, 1986, p. 415).

The idea of participating in health promotion is the corner stone for empowerment: citizens can help themselves and each other to remain healthy, which is the base for a democratic bottom-up approach. There is however another side to the coin. At the time, researchers in economics were often interested in finding new ways to minimize the costs for the public sector. Osborne and Gaebler were two neoKeynesian economists who saw public participation in the public sector as one way to go, and tried to change the activities of the state organisations from the role of the expensive producer to a controller of services instead. They invented the slogan "steering, not rowing", which was built on the idea of public participation in activities which the state and the county councils earlier had the total responsibility for (Osborne and Gaebler, 1992). With this background the idea of participation in health promotion lost at least some of its radical character, and became more of a general liberal program for governing the public sector.

Therefore, it should not be forgotten that Ottawa charter also has a radical discourse built on the modern ideals of freedom, of social equality and justice. At the Ottawa conference in 1986, Ilona Kickbush emphasised the necessity of equity in health matters to reach the goal of health for all:

Equity to secure for people equitable access to the prerequisites for health: adequate income, decent housing, 
sufficient food and a safe environment which also means freedom from threat of war. It should also give priority to people who do not have the bare essentials for maintaining health, with affirmative action to ensure that discrimination because of sex, ethnicity, age, geographic location, low income or unemployment does not occur (Kickbush, 1986: 438).

Since 1986 equity has been another cornerstone in health promotion, which for a good reason is said to give the research area a radical character. However, it should, not be forgotten that the same approach can also be found in Jake Epp's speech in Ottawa, where he said:

Who are the people at the greatest disadvantage? Native people, some elderly (especially women), immigrants, and single mothers with young children are those with the most serious problems. What they have in common is the less easy access to things that contribute to health-affordable housing, good food, accessible transportation, social support, and community services. Lack of income and unemployment or under-employment is often behind these problems of access. Such circumstances produce the stress and anxiety that can reduce health status. My Government is firmly committed to social justice, these times of fiscal restraint not-withstanding (Epp, 1986: 414).

The fiscal restraints, which probably gave conservative politicians the inspiration for public participation in health issues, were not the only reason for their interest in health promotion. Since both researchers and politicians from different parties seem to share the values of social and economical equality and equity, there appears to be a mutual understanding of at least some of the values. These concepts are not "ideology" in its proper sense of representing a specific social interest or political party. Instead the shared values seem to represent a general "Modern" discourse, which was described by Jürgen Habermas in 1985. The term "Modernity" has been attached to many ideas for more than two centuries, like development of production forces, improvement of work productivity, establishing of centralized political powers, formation of national identities and rights to take part in politics for all citizens. It has also, which is important in this matter, been connected to special norms and values of universal social equality and justice for all citizens (Habermas, 1987). These modern values can be seen as present and shared by all participants in health promotion discussions, which almost always are characterized by the general idea that health issues in society should develop. A frequently used term to describe contemporary Western society is "post-modern", but that concept has often had the aim to describe modernity as a narrative, and a development with a negative impact on the life of ordinary citizens. Bruno Latour has described the negative effects of modern technology on the minds of modern citizens: "No technology without rules, without signatures, without bureaucracies and stamps. Law itself is no different from the world of technologies: it is the set of the modest technologies of writing, registering, verifying, authenticating that makes it possible to line up people and statements" (Latour, 1986: 45).

The same analysis could probably be used to describe the negative effects of 
Public Health and Health promotion research, which often tries to change the behaviour of ordinary people. Using Foucault's theory on power, Vallgårda (2003) describes the Nordic state health policies during the last century. However, no competing policy solution is presented there. The normative base for public health research in general and health promotion in particular, is still to change the health opportunities for many to the better, to fulfil the promises of a Modern discourse. Therefore, the health promotion discourse in this article is seen as Modern, rather than post-modern.

The modern discourse has been described differently, though. The Swedish historian Sven-Eric Liedman found a difference between a smooth and idealistic modernity influenced by a positive view on mankind that cares about the thoughts of ordinary people and never tries to force them to accept modern development and progress. He has also shown a different and harder version of modernity, which would progress faster with no trust for ordinary people's abilities to take care of their own development (Liedman, 1997). On a lower societal level there are still different social interests and opposing political ideologies and parties, which seem to constitute the background for the two discourses in health promotion, visible since the start in Ottawa in 1986. We will compare the two discourses in the Nordic countries, with a special interest for alcohol promotion issues. There is a difference between the Nordic countries in health policy documents, already shown by Vallgårda (2007).We ask if this is the case with peer reviewed research articles as well.

\section{Material and method}

The material for this literature study was collected from three separate searches in the databases ISI, PubMed, Cinahl and CSA. The first search was made only in the ISI database, originally intended for another study, using the names of the public health institutions in the Nordic countries as an address. While working with the material it became apparent that the abstracts on alcohol issues clearly differed between the Nordic countries when the impact of alcohol consumption on public health was discussed. To show the differences in general approach towards alcohol in the Nordic countries, some of these abstracts are described in this study. However they should be seen only as examples of the perceived differences.

The second search was made to show the general differences between health promotion researches in the Nordic countries. The four most important databases for peer reviewed research articles were used: ISI, PubMed, CINAHL and CS-the latter contains the slightly smaller databases PsycInfo, Social Services Abstracts, Social Work and Sociological Abstracts. The search word was "health promotion" as keywords (or as Mesh-term in PubMed), and addresses in some of the five Nordic countries.

The use of institutional addresses to define a national background for an article is often difficult with the growing tendency of international collaborations and immigration of today. Some of the "Danish" articles are collaborations with Kenneth Mukamal, who is an American researcher working at Harvard University. Some "Swedish" reports are made in collaboration with Harry Holder, who is an American as well, working at a Government institute in California. This study still uses author affiliation/ 
addresses as search criteria; otherwise the work to define actual nationality of the authors would lead to micro-sociological and ethnographic perspectives, which is of no interest for this study. Only articles written in English were used, which excludes material written only for readers in the Nordic countries. Using the time period from 1986 to 2008, 1863 articles were found, after exact duplicates had been sorted out. 303 abstracts were chosen, and for that study only abstracts using common terms in health promotion research have been coded; 13 articles contains the words intersectoral, 36 articles contains the word multidisciplinary, 194/31 articles contains either participation or participatory and 18/11 articles contains the word sustainable or sustainability. Only 258 abstracts were coded since some articles had no abstracts, or were copies. The findings in this search can be seen in the general Health Promotion figures 1 and 2.

The third search was made in the new database containing the 1863 Nordic health promotion articles mentioned above. The search word was "alcohol", and 164 articles were found. Those abstracts with alcohol merely as one of many health issues were sorted out. Only the "pure" alcohol articles were used for this study, the reason being that the aim was to find the different discourses specifically in Nordic alcohol research, and 36 were found. The findings in this search can be seen in the alcohol Health Promotion figures 3 and 4 .

The study is inspired by the Strong as well as the Weak Program in sociology of science, and analyses the literature based on an understanding of the social interests and national/cultural differences in alcohol research. Primarily it is not an "evaluation" of the quality in the research projects. Since they all have been published in peer reviewed research journals, they are in this study treated as equal in quality-even if researchers in health promotion might have a different opinion on that aspect.

This perspective is common in science studies based on the Strong Program, which consider science to be a cultural activity and make "symmetrical" science studies with a neutral approach to truth claims from different researchers (Bloor, 1976, Shapin and Schaffer, 1985). A totally neutral approach to health promotion research is not sought after in this study, since it is an activity with an important impact on policy and regulations in many nations. This is not only the case for health promotion research; Karin Knorr-Cetina has depicted the direct contacts researchers in some areas often have with financiers from government and industry, and discussed how it affects the ideal of an objective and neutral researcher (Knorr-Cetina, 1982, KnorrCetina, 1999). The importance of Public Health research for policy issues, which will have a direct impact on the life of ordinary citizens, makes it difficult to have a neutral approach in these matters.

Therefore, we will in this article discuss the findings from a "modern" normative perspective. Brian Martin introduced a non-neutral approach; "the standpoint of the citizen" as a norm for science studies of this character, which resembles a "modern" perspective on these issues (Martin, 1993). This approach is also closer to the so called Weak Program defined by Chubin \& Restivo who were not interested in the truth claims of different researchers but emphasised the actions people take based on those claims, i.e. they had more interest in the effects of research on policy issues (Chubin and Restivo,1983; Restivo, 1994).

The study started from a finding that alcohol research in public health differed between the Nordic countries, which 
lead to the question if a difference could be found in health promotion articles in general, and then specifically in alcohol health promotion articles. Abstracts from the articles have been coded with SPSS, based on the understanding that health promotion is built up on several different academic disciplines, using both quantitative and qualitative methods. Research projects also have different target groups, and a difference between a top-down or a bottom-up perspective on the activities can often be seen. A top-down perspective in this context implies that the initiative for the research comes from the researcher or from the authorities, and that ordinary citizens are not supposed to collaborate on an equal level. A bottom-up perspective means the contrary: ordinary citizens, adolescents or patients are involved in the study and contribute to the design and outcome of it. Many studies are either top-down or bottom-up, but some balance between these two extremes and consequently were coded for both. Finally, the abstract was coded for different aspects on relevance, such as 1) descriptive, 2) relevance for other researchers, 3) for individuals, 4) organisations, 5) sectors (like county councils), 6) for government policy, and 7) for changes or control of laws and regulations-the latter aspect was not very common.

The alcohol articles have been read in full length for the qualitative part of the study. A literature study always contains a hermeneutic approach; reading and analyzing text does not produce any objective results. It is built on a preunderstanding of the subject. Therefore the results should not be seen as verifying a theory in an absolute objective sense, but rather as an attempt to give a new understanding and be a base for further debate on the role of Nordic health promotion.

\section{Public Health research and alcohol in the Nordic countries}

A brief reading of abstracts in Public Health from the Nordic countries, and not only the limited Health Promotion area, show that there is a general difference between the countries in approach towards alcohol. The view that alcohol is a dangerous drug is often seen in articles written by Swedish authors. It can be the cause of breast cancer:

Conclusion: The observed association between risk of developing postmenopausal estrogen receptor+ (ER) breast cancer and alcohol drinking, especially among those women who use postmenopausal hormones, may be important, because the majority of breast tumours among postmenopausal women over-express ER (Suzuki et al, 2005).

This viewpoint can be compared with a Danish abstract, which instead considers that wine may prevent cancer:

There was no association between beer or spirits drinking and gastric cancer. In conclusion, the present study suggests that a daily intake of wine may prevent development of gastric cancer (Barstad et al, 2005).

Researchers in Public Health and Health Promotion will most likely protest to this, declaring that breast cancer and gastric cancer are two different diseases. This is a valid argument, but we have to remind the reader that the aim of this study is not to evaluate the articles, but to find and analyse the social and cultural differences in research articles. In general, there is a difference between the standpoints held by Swedish alcohol researchers compared 
to many Danish, since alcohol in Sweden is often seen as a threat.

This perspective can be found in a report published by the Swedish Institute of Public Health, with the American researcher Harry Holder as the first author. Table 1, taken from that report, aiming to show what will happen in the Swedish society if the alcohol monopoly will be abolished, and alcohol instead will be sold in private specialty shops, or in ordinary grocery stores (Holder et al, 2007).

According to the report an abolition of the Swedish alcohol monopoly will lead to serious health problems. The standpoint, stressed by many Swedish researchers, is that alcohol is a serious threat not only for alcohol addicts, but for the health of all citizens.

In Denmark alcohol is more often considered as prevention. As already has been shown, alcohol is sometimes seen as preventing cancer, and in this article, where Danish researchers collaborate with the American researcher Kenneth Mukamal, it is also seen as preventing heart disease:
Conclusions-Alcohol intake at least 3 to 4 days per week is associated with a lower risk of myocardial infarction among women and men, an association apparently attributable to the relationship of alcohol with HDL cholesterol, fibrinogen, and hemoglobin Alc. Because the effects of alcohol on HDL cholesterol, fibrinogen, and insulin sensitivity have been confirmed in randomized trials, our findings support the hypothesis that the inverse relation of alcohol use and myocardial infarction is causal (Mukamal et al, 2005).

In this Danish article moderate alcohol consumption also gives a lower risk for stroke:

Conclusions: This study indicates that the apparent lower risk of stroke associated with moderate alcohol consumption is confined to a group of highly stressed persons. It is suggested that alcohol consumption may play a role in reducing the risk of stroke by modifying the physiological or psychological stress response (Nielsen et al, 2005).

\begin{tabular}{|l|c|c|c|c|}
\hline Type of Harm & $\begin{array}{c}\text { Private } \\
\text { liquor stores }\end{array}$ & Increase & $\begin{array}{c}\text { Grocery } \\
\text { Stores }\end{array}$ & Increase \\
\hline $\begin{array}{l}\text { Deaths from explicitly } \\
\text { alcohol-related illnesses }\end{array}$ & 430 & $26 \%$ & 1000 & $61 \%$ \\
\hline Fatal accidents & 120 & $10 \%$ & 250 & $22 \%$ \\
\hline Suicides & 130 & $14 \%$ & 290 & $30 \%$ \\
\hline Homicides & 20 & $18 \%$ & 40 & $40 \%$ \\
\hline $\begin{array}{l}\text { Total number of deaths } \\
\text { from specified causes }\end{array}$ & 700 & $18 \%$ & 1580 & $41 \%$ \\
\hline Assaults & 6700 & $10 \%$ & 14200 & $22 \%$ \\
\hline Sick days & 7300000 & $18 \%$ & 16100000 & $40 \%$ \\
\hline
\end{tabular}

Table 1: Annual harm from the alcohol consumption increases resulting from privatization estimated using Swedish time series data 
If this explanation of the psychological effects of alcohol is connected with the more biological explanation in the abstract above, the question is if the Swedish aim to generally lower the alcohol levels in society will have a positive outcome for the public health. Instead, for promoting health in society, it appears to be of importance to consume alcohol moderately. We will now present an overview of the different underlying views observed in Nordic health promotion articles.

Figure 1

\section{Health Promotion research the Nordic countries}

When 258 abstracts in Nordic health promotion research where coded (containing thewordsintersectoral, multidisciplinary, participation/participatory and sustainable/sustainability), differences in perspectives between Nordic countries were seen. Figure 1 visualizes that Finland and Sweden are more top-down, Norway and Denmark are more bottom-up (we will not comment on Iceland since the material from this country is very limited).

\section{Perspective in Health Promotion Research in 5 Nordic Countries}

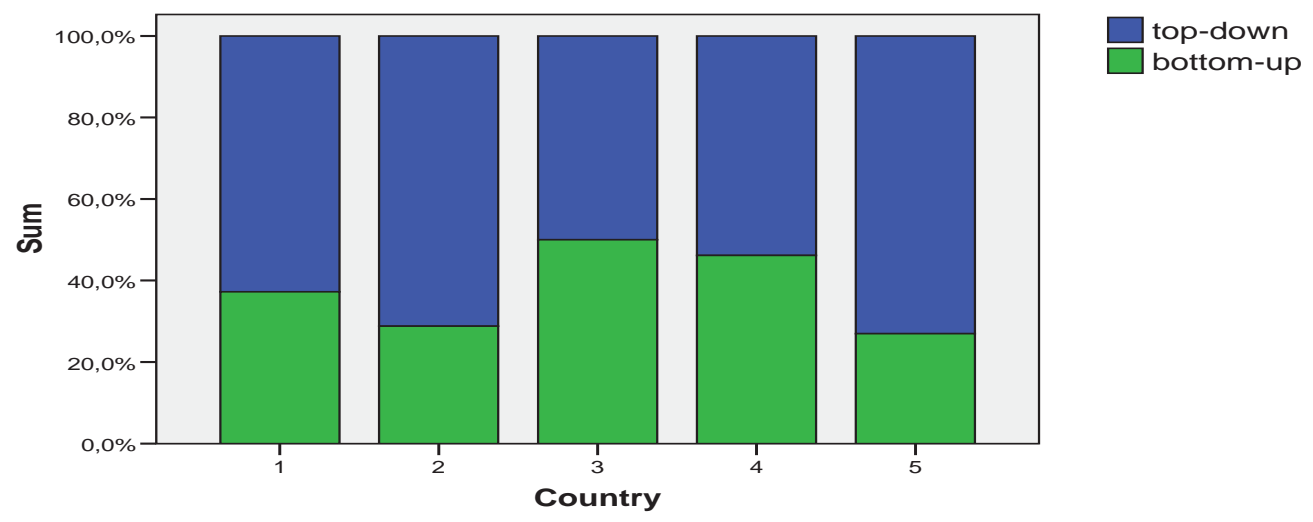

$1=$ Denmark $2=$ Finland $3=$ Iceland $4=$ Norway $5=$ Sweden

Figure 2

Levels in Health Promotion Research in 5 Nordic Countries

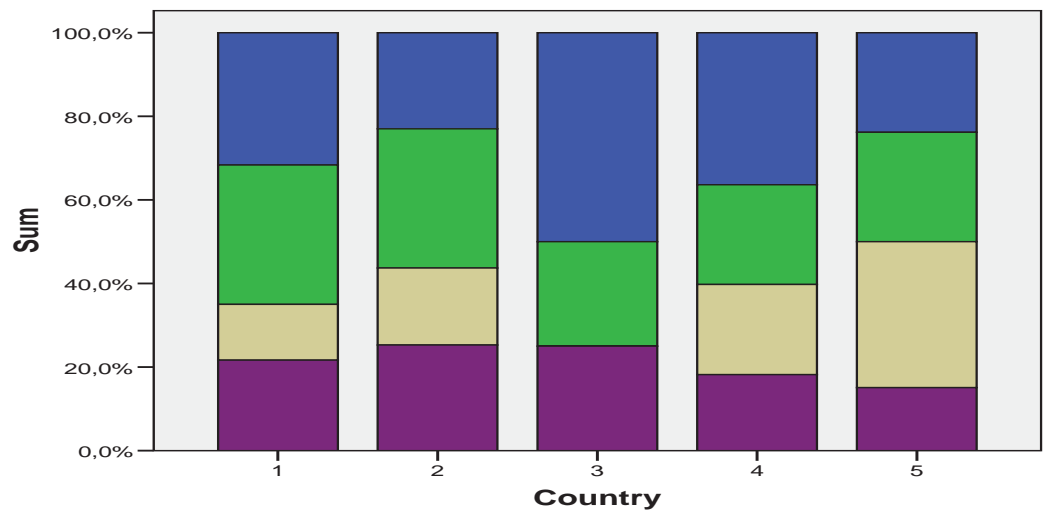

Individual

Organisation

Community

National

$1=$ Denmark $2=$ Finland $3=$ Iceland $4=$ Norway $5=$ Sweden 
Figure 2 shows that Sweden and Finland tend to have a similar research profile, and Denmark and Norway a slightly different, when the general level is measured, i.e. how the research projects are designed according to individuals, organisations, communities or nations:

\section{Alcohol health promotion in the Nordic countries}

Sweden and Finland tend to have a topdown approach in health promotion research and it became very clear when the 36 "pure" alcohol articles were coded with the same method. Figure 3 show that all alcohol health promotion research articles have a top-down perspective in Sweden:

Figure 3

Perspective in alcohol health promotion research in 5 Nordic countries

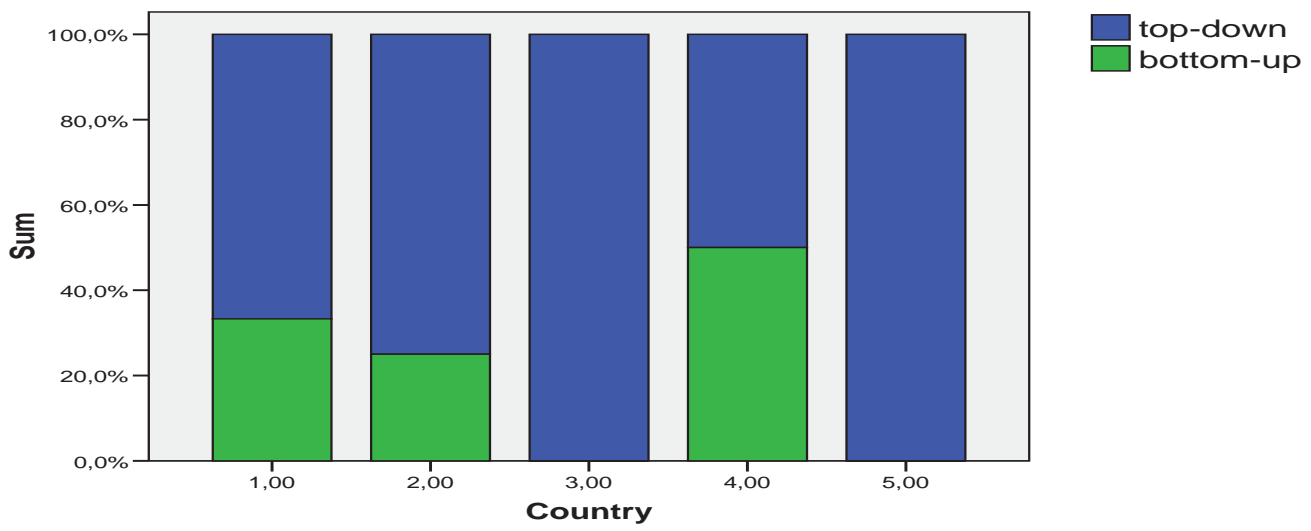

$1=$ Denmark $2=$ Finland $3=$ lceland $4=$ Norway $5=$ Sweden

Figure 4

Relevance in alcohol health promotion research in 5 Nordic countries

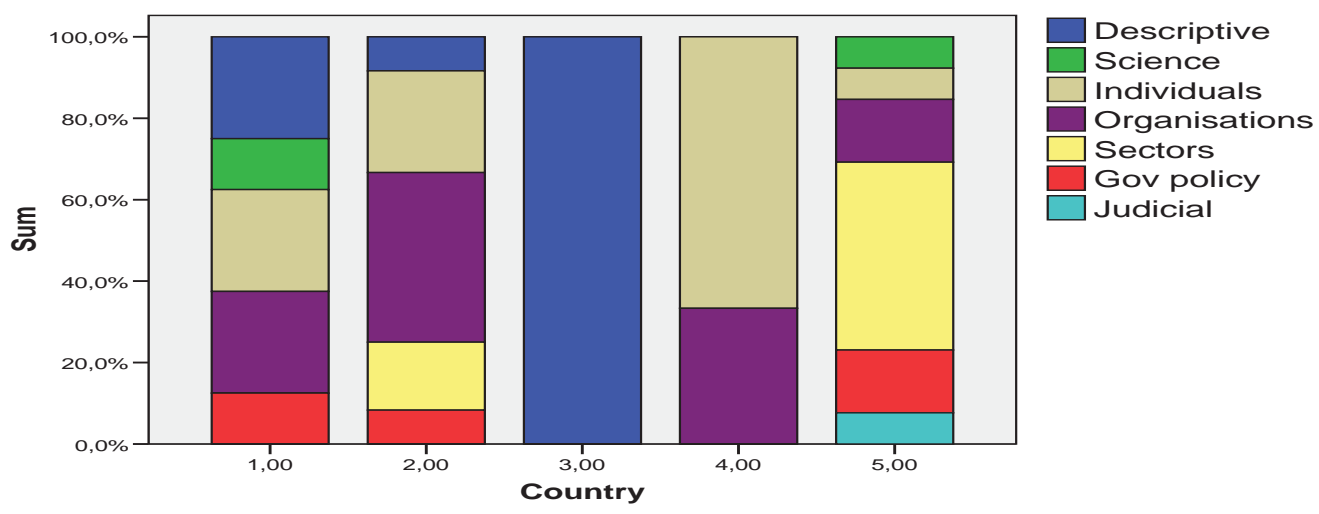

$1=$ Denmark $2=$ Finland $3=$ Iceland $4=$ Norway $5=$ Sweden 
There is also a special characteristic in Swedish alcohol promotion research, apart from the strong top-down perspective. Figure 4 visualizes that Swedish researchers tend to have a more obvious relevance for "sectors", which in this context means county councils and ccommunities, and also more often have relevance for laws and regulations (judicial).

Figure 4, which represents an overview of alcohol health promotion articles in the Nordic countries, shows that there are small but distinct differences between the countries. Selected examples of the tendencies from abstracts provided even more extreme differences, although the differences generally are minor. Since only a few articles on alcohol health promotion derive from Iceland, Norway and Finland, we will focus on the Danish and Swedish material. However, if there is a cultural understanding that alcohol is a threat for the health of the citizens, the aim for alcohol health promotion ought to be to minimize the level of alcohol intake in general. This view has already been described as the "total consumption approach" and can be found in some abstracts from Sweden (Tigerstedt, 2000). It is based on the idea that a lower alcohol level in general will result in less alcohol problems:

Our aim was to study socio-economic differences in awareness and knowledge about the Kirseberg Project and in attitudes towards the concept of health as a local community issue. The Kirseberg Project was initiated in 1988. The primary prevention aims are to reduce alcohol consumption in the population in order to decrease the incidence of alcohol-related problems (Goransson et al, 1996).
One method to minimize the level of alcohol in society is to create laws and regulations. As can be seen in the overview of relevance aspects in health promotion research, Swedish researchers more often show an interest for alcohol regulations. This is also shown in the quote below:

Conclusions: There has been a significant improvement in the rate of refusal of alcohol service at licensed premises in Stockholm during the project period. The reason for this is probably a combination of the intervention efforts: community mobilization, RBS training and a more efficient monitoring of alcohol service by authorities (Wallin et al, 2005) .

In Figure 4 the viewpoint that regulations will solve alcohol problems, is not so often found in alcohol health promotion articles in the other Nordic countries. In the project, bartenders and service personnel are trained to refuse to sell alcohol to adolescents and guests already under influence of alcohol at restaurants, which can be seen as a bottom-up approach. This is however coded as a topdown project since authority rules had to be followed and guests and adolescents are not involved.

The perspectives on alcohol in health promotion in articles from Denmark are often different compared to Sweden. Alcohol is not seen as a threat in the same way; instead harm-reducing programs are considered to be more effective. However, this is not a specific "Danish" ethnic view; an English researcher from WHOs regional office in Copenhagen wrote in 1994:

All of the dependence-producing substances are capable of causing harm but in most cases the harm 
is preventable. This paper seeks to develop some of the themes raised by the five substance-based prevention papers by presenting an outline of the Ottawa Charter for Health Promotion (Anderson, 1994).

The idea that the harm of dependenceproducing substances in most cases are preventable, and the Ottawa Charter remark, which relies more on the individual's power to handle his/her own health, must result in a different view on alcohol promotion work. Campaigns to teach people about their "sensitive limits" had a good outcome in Denmark, according to Danish researchers:

In Denmark, a campaign has been repeated every week 40 from 1990 to 2001 with information on the sensible drinking limits of 21 drinks per week for men and 14 drinks per week for women... // ... We conclude that public health campaigns, such as the sensible drinking limit campaign, certainly has an impact on the level of awareness in the general population. Furthermore, those drinking more than 21 and 14 drinks per week, respectively, are reached by these campaigns (Gronbaek et al, 2002).

According to Ottawa Charter educated people should be able to take care of their own health issues. This opinion makes Danish alcohol health promotion quite different from the Swedish. This is also the case with teenagers and alcohol. We have already seen an example from Sweden, which aimed to strengthen the control of alcohol regulations in restaurants. In Denmark the view on use of alcohol by younger teenagers (between 13-16 years) is very different:
The informants monitored their own level of intoxication, but in order to reduce alcohol consumption they depended upon support from their peers. The informants preferred drinking in the company of wellknown and trusted peers, and during drinking episodes they supervised and intervened in each others' drinking to the extent that they deemed it necessary and possible. In regulating the social context of drinking they relied more on their personal experiences than on formalized knowledge about alcohol and harm, which they had learned from prevention campaigns and educational programmes. Conclusions: In this study we found that teenagers may help each other to minimize alcoholrelated harm, and teenage peer groups should thus be considered a resource for health promotion (Jorgensen et al, 2007).

A research project with the viewpoint that teenagers can monitor their own level of intoxication, and that other teenagers can help to minimize the harms of alcohol, would probably find it impossible to find funding in the Swedish context. In Sweden teenagers should not drink alcohol, and it is often discussed in daily newspapers if families should apply zero-tolerance for alcohol for teenagers under 18 years. The standpoints in the abstracts presented above differ dramatically, but as shown in the overview figures above, the general differences between the countries are not that great. Still they are present, and the question is whether it is possible to find a common policy for the Nordic countries. Other questions that need to be asked are; what is the reason for the difference, can a joint Nordic policy be discussed, and is it possible for Nordic researchers to learn from each other? 


\section{Discussion and conclusions}

The theoretical background for this article was inspired by the Strong and Weak Program in sociology of science, and the aim was to describe the social and cultural differences between alcohol health promotion articles in the Nordic countries. Science studies following the Strong Program are not to be seen as evaluations, because they often shows less interest for the quality of a study, the actual facts behind the claims, or the eventual "objective" effects of a research project. This point of view can of course be questioned in the area of health promotion, since the gap between research and political decisions often are much smaller, compared to many basic research areas. If we change our viewpoint from the descriptive approach of the Strong Program and instead use a policy-oriented Weak Program approach for understanding these issues, the statistics from the Nordic countries show that there are difficulties with the Danish more liberal view on alcohol, and health matters in general. In 2000 a joint Nordic project reported about the differences in health and life expectancy between Sweden and Denmark. The conclusion was that Denmark had fallen to the bottom in the 1990s while Sweden was still ranking high within the OECDcountries. It pointed out the fact that smoking and alcohol consumption were twice as high in Denmark compared to Sweden (Isacsson and Krasnik, 2000).

These differences in health and life expectancy, when compared to the levels of tobacco and alcohol consumption, are certainly a problem for the liberal approach in Denmark. But there are also problems with the Swedish approach to alcohol health promotion, being based on alarm reports, which sometimes lead to strong regulation and zero-tolerance. A Finnish study depicted the problems with restrictions and zero-tolerance. Even if these actions have a popular appeal, they delegate the responsibility downwards from managers to field workers and finally parents and schools, even if harm reduction programs can be more effective (Sulkunen et al, 2004). The actions seem to be effective in official declarations and programs, but the risk that it will be ignored by teenagers and other people in real life remains. This is a problem for the Swedish approach, which ought to be discussed by Swedish health promotion researchers.

The findings present two different discourses in the Nordic countries, not only in alcohol promotion but in health promotioningeneral. FinlandandSweden often have a top-down perspective, while Denmark and Norway are bottom-up oriented. What causes these differences? This question has already been asked by the Danish researcher Rosta in a discussion on the differences, not between the Nordic countries, but between the German and Danish alcohol policies. According to Rosta there is an ideological background for these strategies and the Danish viewpoint is connected to medical circles in Denmark, but in Germany temperance groups, supported by the ruling conservative party, plays an important role for alcohol policies. Medical researchers are middle class people who live on a distance from the social problems with alcoholism. But religious movements in Northern Germany, who have a strong impact on temperance groups, have a very different view on alcohol, which is not so easily influenced by medical research findings (Rosta, 2003).

A perspective balancing between the Strong and Weak Program in science 
studies on these issues gave the result that social interests play a role in the construction of the negative and positive views on alcohol. Temperance groups probably have more influence on alcohol policy in Sweden, compared to their role in Denmark. Not only conservative parties are negative towards alcohol in the Swedish society-the Swedish social democratic party has an organisation (the Christian Broderskapsrörelsen) with a restrictive approach to alcohol consumption. Since the funding of many large research projects in Sweden is guided by public authorities with political representatives, and since the peers in the committees are citizens in their own culture, it will probably be quite difficult for a Swedish researcher to set up a project with a positive view on moderate alcohol consumption. The same problem would probably occur for a Danish researcher who wants to present a zero-tolerance oriented alcohol project in Denmark. As a result many researchers are transformed to passive verifying instruments for the existent culture, and the ideal of the independent truth seeking researcher has to be abandoned.

One important finding in this study is that if the two different perspectives in Denmark and Sweden are compared to the basic viewpoints in Ottawa and Bangkok Charter, it looks as if the two countries are not following specific cultures, but rather two discourses. The Ottawa (bottomup) approach is present in Denmark: the view is close to the "strengthening of public participation in and direction of health matters". Sweden instead looks like the Bangkok (top-down) approach, which rely on "strong intergovernmental agreements and government incentives and regulations". The differences cannot be said to have started recently, being dependent on the discursive change at the Bangkok conference. The differences instead can be found already in the late 1980 s, and therefore seems to give a picture of the two discourses working side by side already from start in the Ottawa Charter, representing different social interests where liberal politicians saw a chance for cost reductions in the public health sector. More radical researchers stressed the importance of equality and equity issues for the improvement of public health.

One reason for the changes in the Bangkok Charter from 2005 can also be the impact of people from poor countries at the conference, since it seems to be affected by frustration over the slow pace of the health promotion movement. The impact of not only researchers, but also of politicians and administrators from poor countries, and the knowledge of the enormous work these countries face in meeting the standards of the industrialized world, will probably give a different picture of how health promotion should be performed. The top-down approach has a rather negative view on the ordinary citizen's learning abilities. The divide between rich and poor countries and between rich and poor people in the rich world, opens up diverse policies towards people on different levels of social and cultural capital. The question is whether health promotion programs can be managed with a law and order approach for the poor and uneducated and with a more democratic approach for the wealthy and educatedsuch a solution would probably introduce unequal perspectives in the midst of health promotion research.

Nordic health promotion researchers ought to discuss how they can deal with the differences between the countries. As has been pointed out, there are advantages and difficulties with both perspectives and a balance between them might be possible to handle. But 
can the Ottawa and Bangkok perspectives be merged, i.e. a blend of top-down and bottom-up? The more liberal Ottawa approach which rely on ordinary people's strength to take care of their own health issues, and the view that health inequities are unjust, seems to be a good example of the Modern ideal which was briefly discussed in the beginning of this article. A hard Modernity seems to represent the executive part of the state, the administrators and bureaucracy who wants to see results in a limited time period. Compared to Denmark, authorities and state officials in Sweden probably had a stronger position, and this is most likely the case also in many deprived countries today. The bottomup approach seems to be more accepted in countries with a strong classic liberal tradition and represent sentiments often held by middle class people with a higher educational level.

The question is whether the top-down perspective has anything to do with the modern democratic ideals. It should, however, be remembered that Modern ideals were constructed by philosophers, represented an abstract ought-to-be for society's development. This Modern standpoint gives a special role for the expert; it is his/her "superior" knowledge that take the lead for a future to come, and perhaps health promotion researchers must accept their role as being experts on a higher knowledge level. The problem, though, is how much power an expert can use for the good sake of a better future. It seems important that Danish and Swedish health promotion researchers start to discuss these issues. Policymakers must have difficulties in understanding how to deal with the situation, and it must be almost impossible for ordinary citizens to use the contradictory messages in Nordic alcohol health promotion as a guideline for a healthy lifestyle.

\section{References}

Anderson, P. (1994). Overview - PublicHealth, Health Promotion and Addictive Substances. Addiction, 89, 11, 1523-1527.

Barstad, B., T. I. A. Sorensen, A. Tjonneland, D. Johansen, U. Becker, I. B. Andersen \& $\quad$ M. Gronbaek (2005). Intake of wine, beer and spirits and risk of gastric cancer. European Journal of Cancer Prevention, 2005, 25, $14 ; 239-243$.

Bloor, D. (1976). Knowledge and Social Imagery. London: Routledge \& Kegan Paul Ltd.

Chubin, D. E., \& S. Restivo (1983). 'The Mooting' of Science Studies: Research Programmes and Science Policy. In K. D. Knorr-Cetina, \& M. Mulkay, M. (Eds.), Science Observed, Bristol: Sage Publications.

Epp, J. ( 1986). Address - the Honourable Jake Epp. Health Promotion - An International Journal, 1, 4, 413-417.

Goransson, M., B. S. Hanson, E. Lindbladh \& P. Ostergren (1996). Using socioeconomic differences in knowledge and attitudes to shape community alcohol programmes: experiences from the Kirseberg Project. Health Promotion International, 11, 2, 95-103. Gronbaek, M. N., U. Stroger, H. Strunge, L. Moller, V. Graff, \& L. Iversen (2002). Impact of a 10-year nation-wide campaign on knowledge of sensible drinking limits in $\mathrm{D}$ e $\mathrm{n} \mathrm{m}$ a $\mathrm{r} \mathrm{k}$. Ugeskrift for Laeger, 164,49 , 57825786.

Habermas, J. (1987). The Philosophical Discourse of Modernity. (Der philosophische Diskurs der Moderne, 1985). Cambridge, Cambridge Policy Press.

Holder, H. D., E. Agardh, P. Hogberg, T. Miller, T. Norstrom, E. Osterberg, M. Ramstedt,., I. Rossow \& T. Stockwell (2007). If Retail Alcohol Sales in Sweden 
were Privatized, What Would be the Potential Consequences? Stockholm, Swedish Institute of Public Health.

h t t p : / / www.fhi.se / upload / ar2008/rapporter_2008/R200827_ Alkoholmonopol_eng_0809 .pdf

Isacsson, S. O. \& A. Krasnik (2000). Sound and unsound around the Sound. A congress report on health differences between Denmark and Sweden. Tidsskrift for Den Norske Laegeforening, 120, 17, 1980-1984.

Jorgensen, M. H., T. Curtis, P.H. Christensen \& M. Gronbaek (2007). Harm minimization a $m \quad o \quad n \quad g$ teenage drinkers: findings from an ethnographic study on teenage alcohol use in a rural Danish community. Addiction, 102, 4, 554-559.

Kickbush, I. (1986). Issues in Health Promotion. Health Promotion - An International Journal, 1, 4, 437-442.

Knorr-Cetina, K. (1982). Scientific Communities or Transepistemic Arenas of Research? A Critique of Quasi-Economic Models of Science. Social Studies of Science 12, 1, 101-30

Knorr-Cetina, K. (1999). Epistemic Cultures: How the Sciences Make Knowledge. Cambridge, Harvard University Press.

Lalonde, M. (1974). A new perspective on the health of Canadians. April, http://www.hc-sc.gc.ca/hcs-sss/alt_ formats/hpb-dgps/pdf/pubs / 1974lalonde/lalonde-eng.pdf.

Latour, B. (1996). Aramis, or The Love of Technology. Cambridge: Harvard University Press.

Liedman, S.-E. (1997). I skuggan av framtiden. Stockholm: Bonnier Alba.

Martin, B. (1993). The Critique of Science becomes Academic. Science, Technology and Human Values vol. 18, No. 2, pp. $247-259$
Mukamal, K. J., M. K. Jensen, M. Gronbaek, M. J. Stampfer, J. A. E. Manson, T. Pischon \& E. B. Rimm (2005). Drinking frequency, mediating biomarkers, and risk of myocardial infarction in women and men. Circulation, 51, 112, 1406-1413.

Nielsen, N. R., T. Truelsen, J. C. Barefoot, S. P. Johnsen, K. Overvad, G. Boysen, P. Schnohr \& M. Gronbaek (2005). Is the effect of alcohol on risk of stroke confined to highly stressed persons? Neuroepidemiology, 29, 25, 105-113.

Osborne, D., \& T. Gaebler (1992). Reinventing Government - How the Entrepreneurial Spirit is Transforming the Public Sector. Reading, AddisonWesley Publ. Co.

Porter, C. (2006) Ottawa to Bangkok: Changing health promotion discourse. Health Promotion International, 22, 1, 72-79.

Restivo, S. (1994) Science, society, and values: toward a sociology of objectivity. Bethlehem, Pa.: Lehigh Univ. Press; London and Toronto: Associated Univ. Press

Rosta, J. (2003). Alcohol in Danish and German educational print-media (1990-1998): A comparison. Addiction Research and Theory, 11, 3, 169-176.

Shapin, S., \& S. Schaffer (1985). Leviathan and the Air pump. Princeton: Princeton University Press.

Sulkunen, P., K. Rantala \& M. Määttä (2004). The ethics of not taking a stand: dilemmas of drug and alcohol prevention in a consumer society - a case study. International Journal of Drug Policy, 15, 5-6, 427-434.

Suzuki, R., W. Ye, T. Rylander-Rudqvist, S. Saji, G. A. Colditz \& A. Wolk (2005) Alcohol and postmenopausal breast cancer risk defined by estrogen and progesterone receptor status: A prospective cohort study. Journal of the National Cancer Institute, 42, 97, 1601-1608. 
Tigerstedt, C. (2000). Discipline and public health. In Sulkonen, P., Sutton, C., Tigerstedt. C., \& Warpenius, K. (eds.), Broken spirits, Power and Ideas in Nordic alcohol control. Helsinki: Nordic Council for Alcohol \& Drug Research (NAD) Publication 39, (pp. 93- 113). http://www.nad.fi/index. php?lang=se\&id=pub/39.

Vallgårda, S. (2003) Folkesundhed som politik. Danmark og Sverige fra 1930 til i dag. Aarhus Universitetsforlag.

Vallgårda, S. (2007). Public Health Policies: a Scandinavian Model? Scandinavian Journal of Public Health, 35, 205211.
Wallin, E, J. Gripenberg \& S. Andreasson (2005) Overserving at licensed premises in Stockholm: Effects of a community action program. Journal of Studies on Alcohol 36, 66, 806814

Stefan Thorpenberg

Nordic School of Public Health

Nya varvet byggnad 25,

Box 12133, SE-402 42 Göteborg

stefan.thorpenberg@nhv.se 